\title{
Characterization and Aerodynamics of Synthesized Polymeric Nanofibers via Electrospinning Process to Capture PM10 and $\mathbf{P M}_{2.5}$ from Air
}

\author{
Baraa L. Abbood, Khalid A. Sukkar*, Jenan A. Al-Najar \\ Department of Chemical Engineering, University of Technology - Iraq
}

\section{Article information}

Article history:

Received: August, 04, 2021

Accepted: October, 19, 2021

Available online: December, 04, 2021

Keywords:

Air purification,

Particulate matters,

Indoor air quality

*Corresponding Author:

Khalid A. Sukkar

khalid.a.sukkar@uotechnology.edu.iq

\begin{abstract}
Air quality is an important factor for human breathing requirements. The presence of the particulate matter which is a mixture of solid particles and liquid droplets presence in atmosphere such as PM10 and PM2.5 in the indoor air leads to fatal problems for human health. In the present investigation, two types of nanofilters (polyacrylonitrile PAN, 15wt.\% and polyvinyl alcohol PVA 12wt.\%) were synthesized using the electrospinning method. The polymeric solutions were prepared under high mixing conditions. The structural and morphological specifications of produced nanofibers were characterized using many measuring devices. Also, airflow characteristics across the prepared nanofilter were evaluated by designing and constructing an airflow apparatus. The apparatus consisted of two stainless steel sections and the middle zone was designed to fit the filter media. The characterization results indicated that the synthesized of PVA $12 \mathrm{wt} . \%$ nanofilter has uniform morphological distribution with fibers average diameter of $92 \mathrm{~nm}$ while the produced PAN with $15 \mathrm{wt} . \%$ showed and an average fibers diameter of $556 \mathrm{~nm}$. Moreover, the PVA nanofilter showed high-pressure values in comparison with the PAN filter. Interestingly, both filters provided high air permeability. Furthermore, the produced PAN nanofilter showed a high ability to capture the PM10 and PM2.5 due to the significant properties and specifications of nanofibers. Additionally, the produced nanofilter can be applied in air filtration processes effectively with low manufacturing costs.
\end{abstract}

DOI: 10.53293/jasn.2021.4101.1070, Department of Applied Sciences, University of Technology

This is an open access article under the CC BY 4.0 License.

\section{Introduction}

Air filtration processes are focused on the environmental concern removal of harmful pollutants from the environment. Air pollution caused by particulate matter $\mathrm{PM}_{10}$ and $\mathrm{PM}_{2.5}$ can cause birth defects, asthma, skin irritation, cancer, and cardiovascular diseases [1-4]. The risk degree highly depends on the level of exposure and the nature of pollutants in the indoors and outdoors air. Usually, the pollution of indoor air is 2-5 times that of outdoor air. Industrial activities such as petroleum production sites, petroleum refineries, petrochemical, and chemical industries can contribute significantly to the increase of PMs in the air [5-7]. Accordingly, air filters are a better choice for capturing various air pollutants. The performance of the air filters is usually determined by the 
type of PMs presented in the air and their concentration [3, 8]. From an industrial application point of view, there are many kinds of air filters such as multi-layers cloth, fiberglass, sponges, and membrane. The electrospinning technology witnessed dramatic extension in the environmental treatment processes due to the importance of these nanofibrous materials in real applications [9-14].

Actually, electrospinning is a method that produces high-quality nanofibers from the injection of the polymeric solution. Usually, the used polymeric solutions have excellent thermal, structural, and chemical stability during the manufacturing process. The selection of nanofilter required managing of size, shape, and chemical structure of these filters to be suitable to capture the PMs [15-20]. Therefore, the nanofilters synthesis process using the electrospinning technique required a deep understanding of the type pollutants (PM10 and PM2.5) and their nature. In other words, the production of fiber materials is usually designed according to the target PM size.

Many papers were published by many authors using different polymer solutions. Chayad et al. [21] evaluated the effect of sodium chloride addition on the specifications of prepared nylon six nanofibers using electrospinning technology. They noted that the conductivity of the polymer solution increased with a slight reduction in surface tension and solution viscosity. Karthick and Gobi [22] synthesized a polyacrylonitrile/silver nanofiber for antimicrobial purposes. The authors noted that the prepared nanofilters provides a high efficiency and a bactericidal activity. Tian et al. [23] produced electrospinning nanofilters using a hydrophobic protein of zein. The protein was dissolved in acetic acid and then was mixed with polyethlyoxid at different concentration 4 wt. $\%, 7$ wt. $\%, 15 \mathrm{wt} . \%$, and $25 \mathrm{wt} . \%$. The authors used a voltage of $16-21 \mathrm{KV}$, distance between needle and collector 10 $\mathrm{cm}$ and flow rate $0.6 \mathrm{ml} / \mathrm{h}$. They noted that with increase a protein load the nanofiber diameter was decreased. Zulfi et al. [24] produced an acrylonitrile butadiene styrene nanofibers membrane for air filtration systems via electrospinning technique using three different solvents. They noted that the prepared a fiber diameter in the range of 210-440 nm with an efficient filtration process of 98\%. Cao et al. [25] investigated air filtration to remove dust particles at a low operating pressure which included a reaction of $0.8 \mathrm{~g}$ of the polysilsesquioxane and $40 \mathrm{~g}$ of the poly lactic acid. The authors noted that as the spinning distance increases, the fiber diameter decreases. Kim and Lee [26] developed an air filter using a polyurethane/polydiacetylene nanofiber which was dissolved in N,Ndimethyl-formamide. They noted that the produced diameters of the fibers from 129 to $254 \mathrm{~nm}$. Then, the authors indicated that the diameters of the nanofibers increased with increase the mass-ratio.

Furthermore, electrospinning technology was used in many important applications in the area of filtration and energy. Barakat et al. [27] investigated nanofiber films can be applied as a hybrid organic semiconducting material. The authors used a thin layer from titanium isopropoxide/PVAc 14\% of dissolved in dimethylformamide at different concentrations using $6 \mathrm{KV}$. They noted that the titanium isopropoxide plays a significant role in electrical conductivity. Also, Oleiwi et al. [28] blended two polymers of PAN/PS and used voltage of $20 \mathrm{KV}$, flow rate 1 $\mathrm{ml} /$ hour, and the distance between a needle and a collector was $15 \mathrm{~cm}$. They noted that with increase the PAN concentration in the blend the hydrophobicity of the membrane and fibers diameter were reduced. It is important to mention here that the size of penetrated PMs into the ventilation system produces a fatal problem in the indoor air quality. Then, many clinical diseases can appear in the human breathing system such as cancer due to these particles activity [29-34].

According to the literature review, there were a few works published on the production of polyacrylonitrile nanofilters (PAN) and polyvinyl alcohol PVA for air purification purposes [35-40]. Moreover, the synthesis process using electrospinning technique required more understanding to explain the influence of the preparation method on the final physical properties of the air filters. Additionally, there was a limited number of publications that deal with the evaluation of airflow characteristics across the prepared nanofilters. Therefore, the present investigation aims to synthesize high-quality polymeric nanofilters for air purifications from PMs using the electrospinning technique. Also, the evaluation of the airflow characteristics across the synthesized nanofilters.

\section{Experimental Procedure \\ 2.1 Materials}

In present work, polyacrylonitrile of (PAN of purity 99.8\% and Mwt. of 150,000) and polyvinyl alcohol (PVA of purity $98 \%$ and M.wt of 80,000) were obtained from the Fluka Company while dimethylformamide of $98.5 \%$ purity was purchased from the Sigma. 


\subsection{Nanofilter Synthesis Procedure}

The preparation of acrylonitrile nanofilter was carried out using electrospinning apparatus (Model-ESB200). Figure 1 shows a photograph of the electrospinning unit while Figure 2 represents the schematic diagram of the electrospinning apparatus. The apparatus includes a high-voltage source with an earthling system and an efficient control system for voltage and temperature. Moreover, the apparatus contains a polymer pumping machine with a high accurate control system for flow measurement to inject polymeric solution at the required polymer flow velocity and has a collection plat for the produced nanofiber. The distance between the needle of the syringe and the collection plate was controlled according to the required distance according to experiment requirements.

The PAN solution was synthesized by dissolving the polymer with the selected solvent of dimethylformamide. The experimental results and testing indicated that the polymer solution of $15 \mathrm{wt} . \%$ is the best concentration for the experiments. Table 1 illustrates the experimental operating parameters for the nanofilters synthesis. The polymeric mixture was stirred in a $200 \mathrm{ml}$ conical flask for $3 \mathrm{~h}$. of stirring time at an operating temperature of $25^{\circ} \mathrm{C}$. Then, a homogenous mixture was produced in this stage. Moreover, the PVA nanofilter was prepared by mixed the polymeric material in the deionized water at concentration of $12 \mathrm{wt} \%$. The polymeric solution was stirred in a $200 \mathrm{ml}$ conical flask under mixing conditions for time of $6 \mathrm{~h}$ at $80 \mathrm{oC}$. Then, a uniform homogenous polymer mixture was obtained and ready for injection in the electrospinning apparatus.

Accordingly, each polymeric solution was pumped using a syringe pump of the electrospinning unit at the specified operating parameters as shown in Table 1 . The produced nanofibers were collected on the collection plate of the apparatus. Figure 3 summarized the various stages of the nanofilter preparation method by electrospinning technique. Additionally, Figure 4 shows a photograph of the prepared samples of the PAN and PVA air filter that were synthesized by electrospinning technique.

Furthermore, many characterization techniques were utilized to characterize the specifications of the prepared nanofilters using a XRD analyzer (Shimadzu-6000) for structural specifications, a FE-SEM (JEOL-7610F) to identify the morphological features and an FTIR analyzer was used to identify the functional groups.

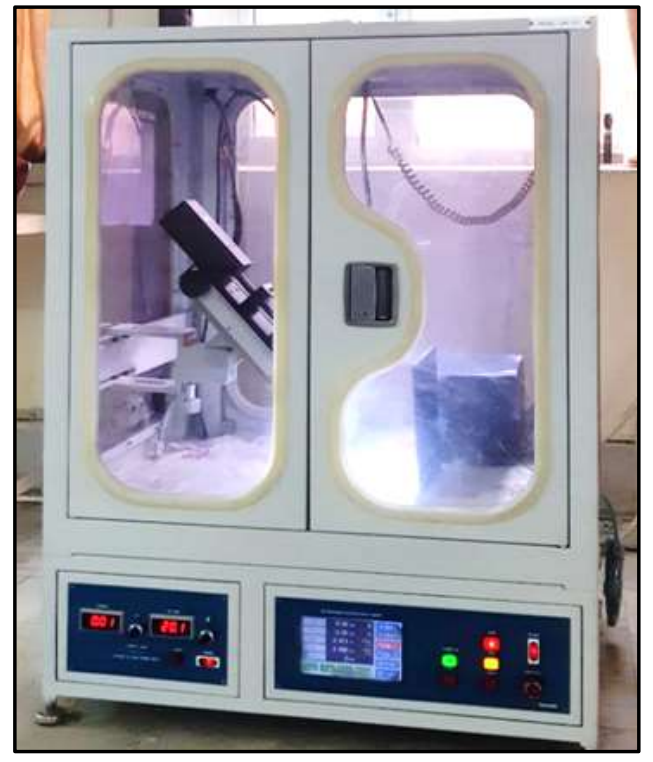

Figure 1: Photograph of electrospinning apparatus for nanofiber synthesis. 


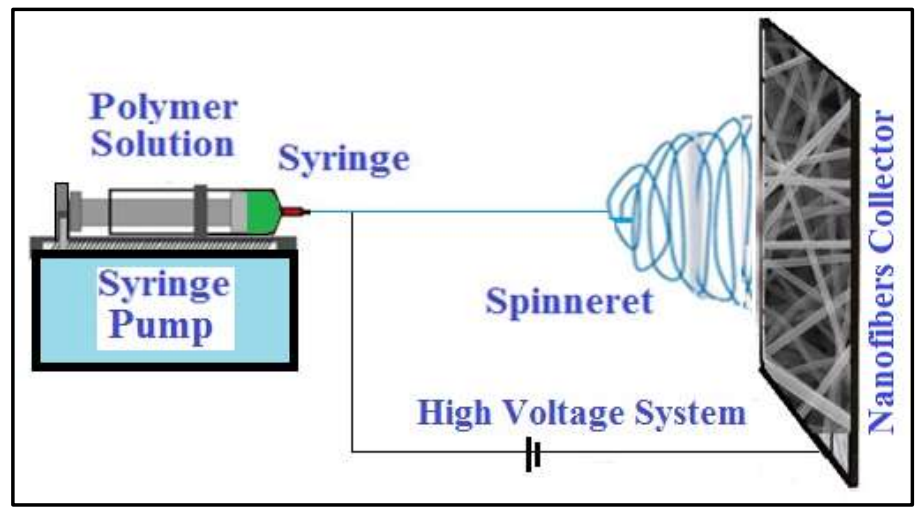

Figure 2: Schematic diagram of the electrospinning apparatus.

Table 1. The operating parameters for the nanofilters synthesis processes.

\begin{tabular}{|c|c|c|c|c|}
\hline $\begin{array}{c}\text { Operating } \\
\text { Parameters }\end{array}$ & $\begin{array}{c}\text { Voltage } \\
(\mathrm{kV})\end{array}$ & $\begin{array}{c}\text { Concentration } \\
(\mathrm{wt} . \%)\end{array}$ & $\begin{array}{c}\text { Distance Between Needle } \\
\text { and Collector }(\mathrm{cm})\end{array}$ & $\begin{array}{c}\text { Polymer Velocity } \\
(\mathrm{ml} / \mathrm{hr})\end{array}$ \\
\hline PAN & 20 & $15 \%$ & 20 & 1 \\
\hline PVA & 25 & $12 \%$ & 20 & 0.5 \\
\hline
\end{tabular}

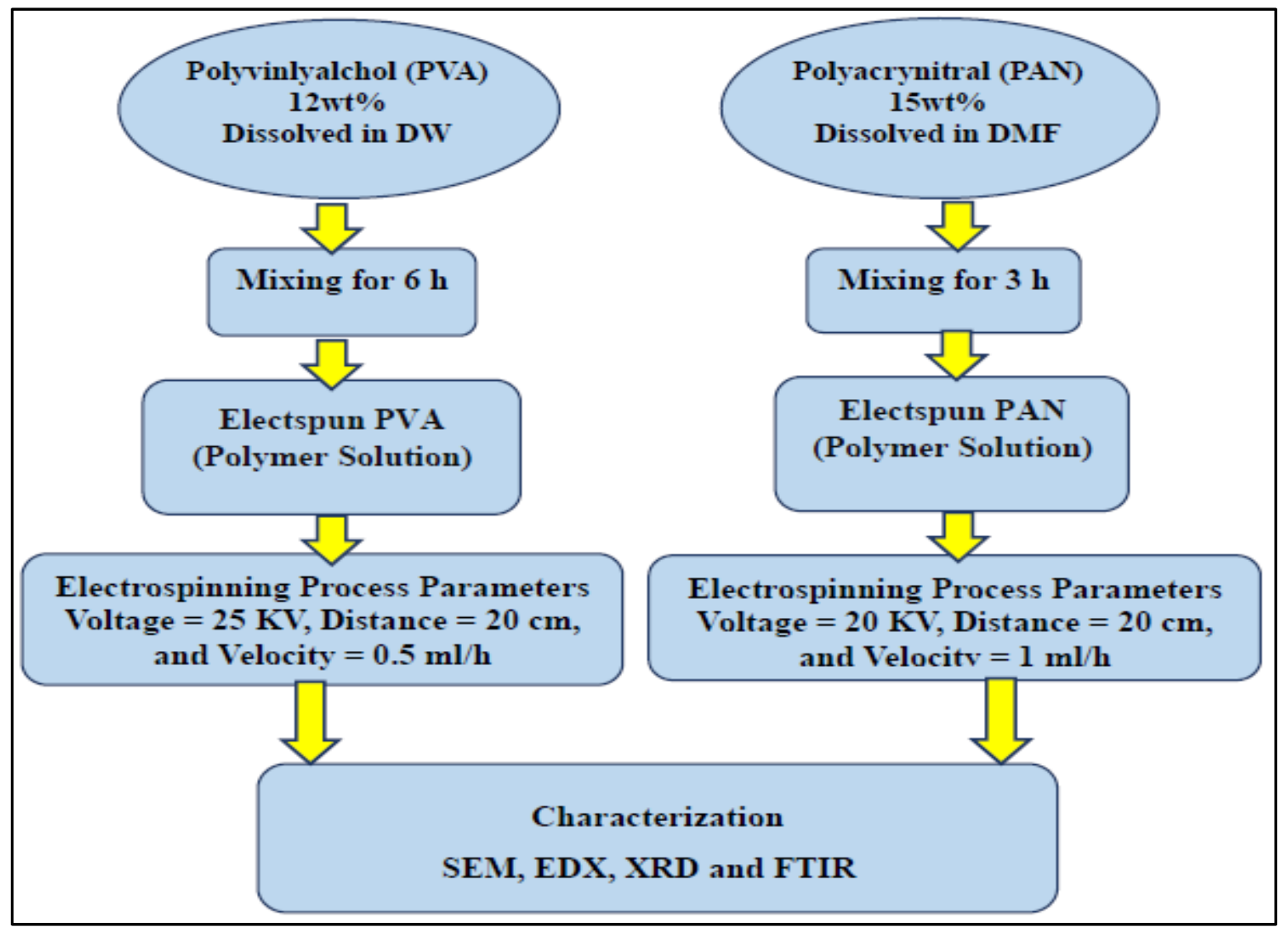

Figure 3: The sequences of preparation stages of PAN and PVA nanofilters via electrospinning technique. 


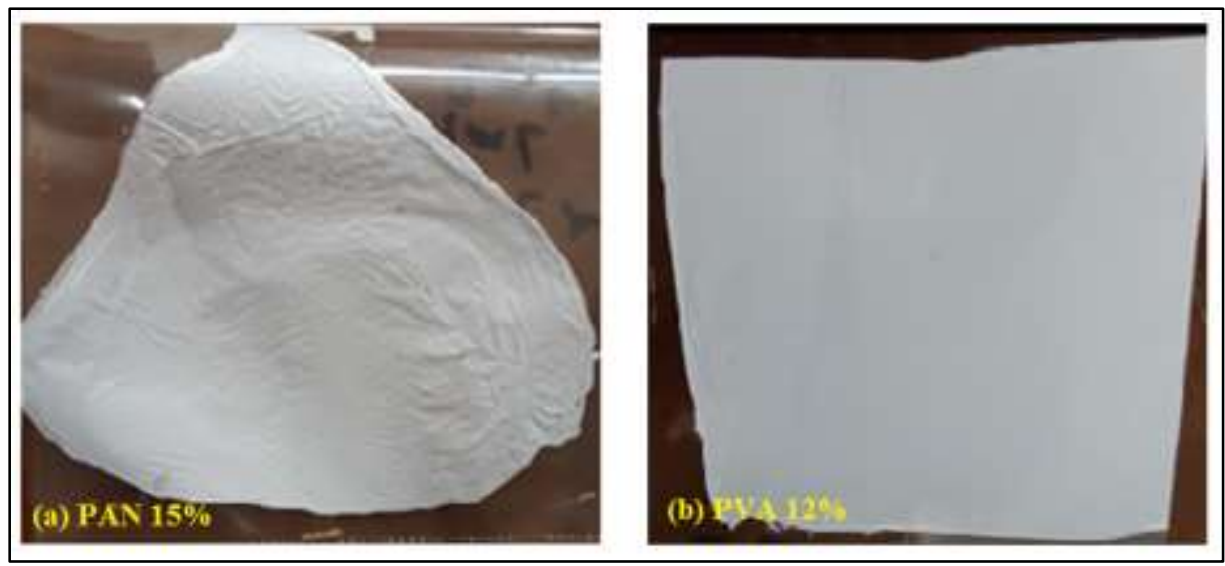

Figure 4: Photograph of the prepared air nanofilters: (a) PAN 15\% and (b) PVA $12 \%$.

\subsection{Air Flow Apparatus}

The air flow characteristics across the prepared air nanofilters were evaluated using an experimental apparatus designed and constructed for this purpose. Figure 5 illustrates the photograph the airflow apparatus, while, figure 6 shows the schematic diagram of the apparatus. The system consists of sections constructed from stainless steel type 316-L of $6 \mathrm{~cm}$ in diameter. The length of the first and second sections was $60 \mathrm{~cm}$ and $50 \mathrm{~cm}$ respectively. The middle zone between the two sections was arranged to support the nanofilter media. The input pollutant air was managed using an air blower fitted at the end of the apparatus. The airflow rate was controlled by employing calibrate airflow meter. The pressure drop was measured on the two sides of filter media using two highly sensitive pressure gauges fitted on both sides of filter media. Also, the pressure was measured using calibrated water monometer supported in the both sides of the apparatus.

The performance of the prepared nanofilters was investigated in the experimental apparatus of the airflow system. The prepared filter material was fitted in the middle zone between the two sections. The experiment was carried out at different air superficial velocities of $1,2,3,4$, and $5 \mathrm{~m} / \mathrm{s}$. Then, the pressure drop was measured at each air superficial velocity. Also, the permeability of each filter material was determined.

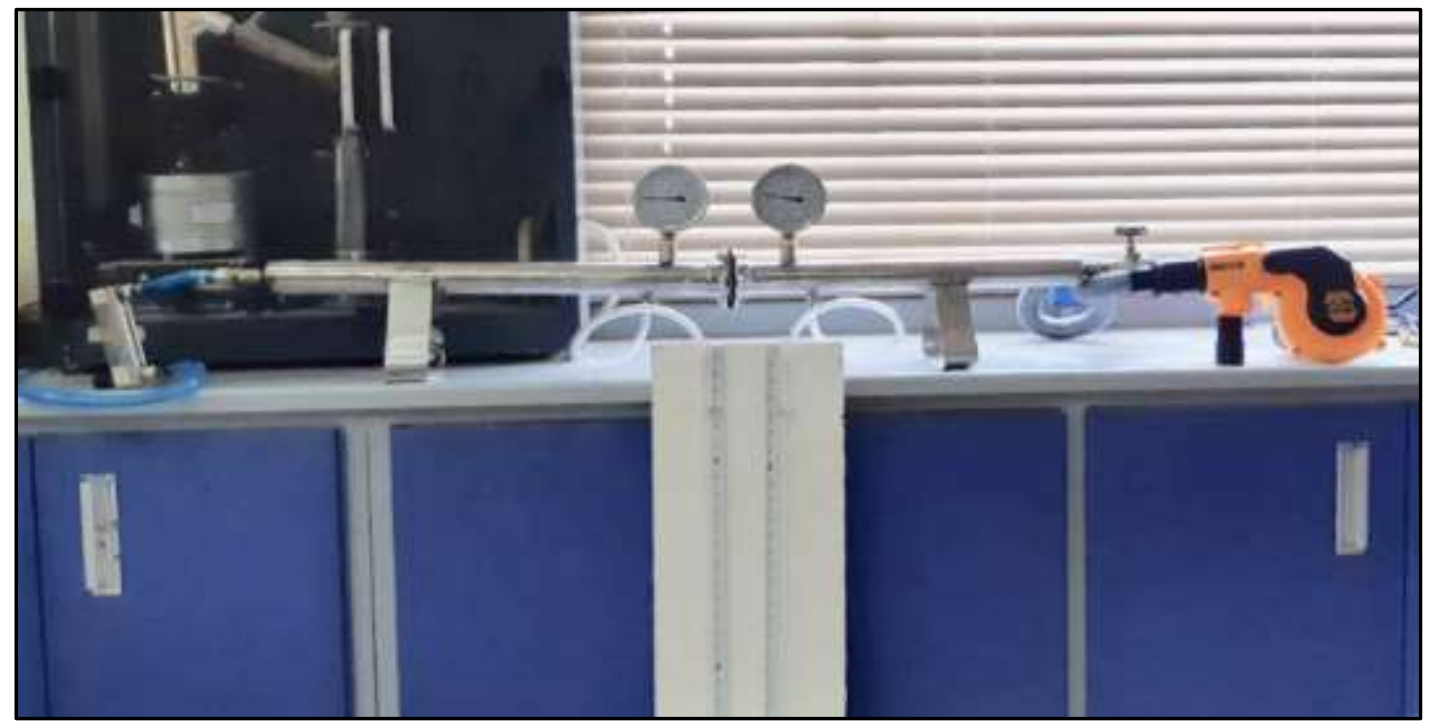

Figure 5: Photograph of the air flow system for nanofilters flow performance measurements. 


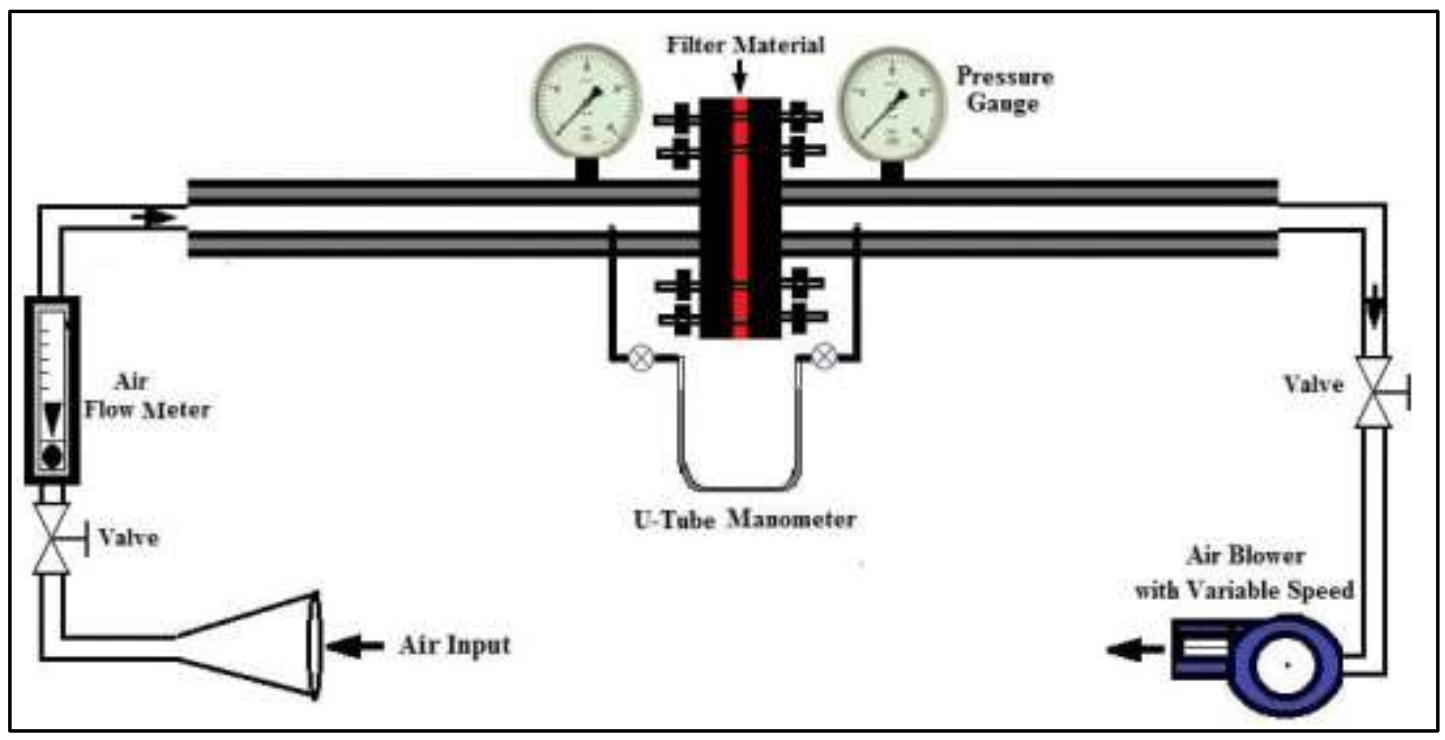

Figure 6: Schematic diagram of the air flow system.

\section{3.3. Results and Discussion}

\subsection{XRD Analysis}

The structure and phases of the prepared nanofilters (PAN and PVA) were evaluated using X-ray diffraction (XRD). Figure 7 shows the structure of synthesized PAN (15 wt \%) nanofilter. The results of the XRD pattern indicated that the overall structure of the synthesized nanofiber is in accord with the standard structure of polyacrylonitrile $[34,35]$. Accordingly, a characteristic diffraction peak for the structure appeared at a $2 \theta^{\circ}$ value of 17. This peak is clear and strong and has a standard position at the phase (100). Moreover, another higher peak was noted at plans (110) at $2 \theta$ equal to 22.6 , this peak is clear and strong.

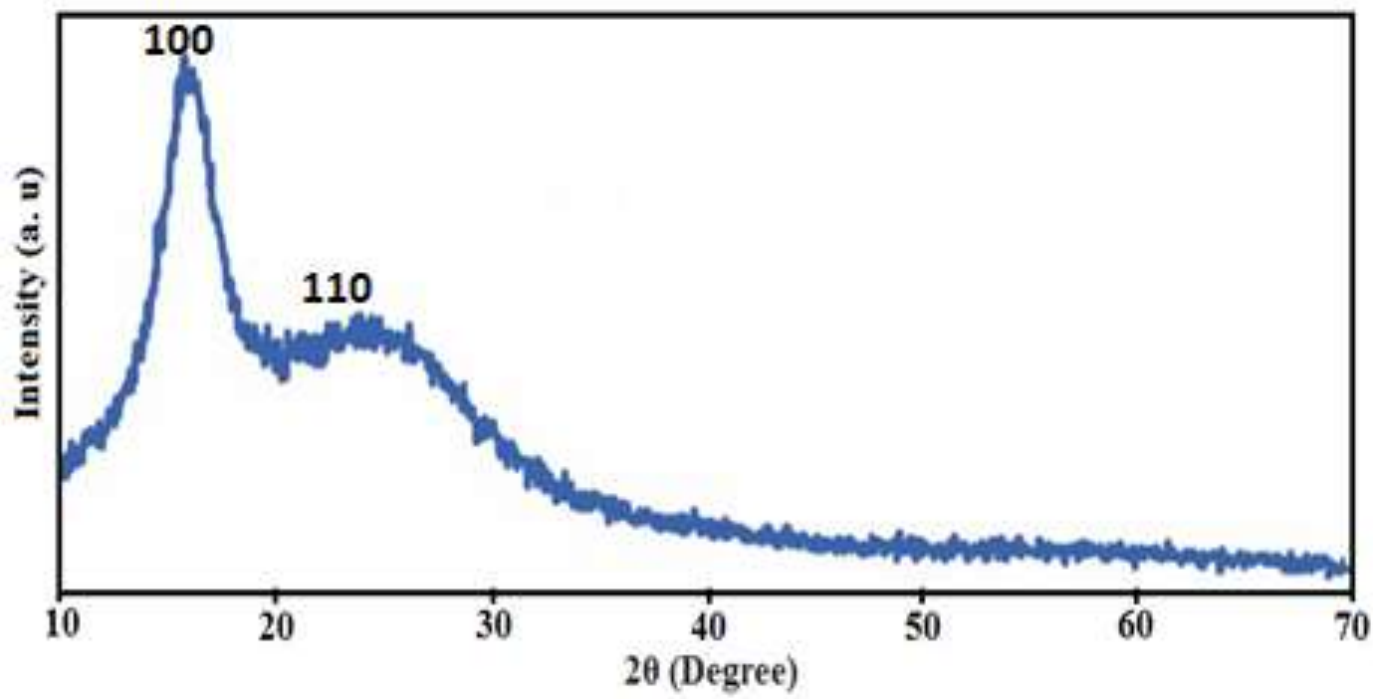

Figure 7: XRD pattern of PAN nanofibers at concentration of $15 \mathrm{wt} \%$.

Also, Figure 8 illustrates the XRD patterns of the synthesized PVA (12 wt $\%$ ) nanofilter and was noted that the general structure of the PVA nanofilter is in accord with standard trends of pure PVA nanofibers. The main broad diffraction peak is noted at the $2 \theta^{\circ}$ value equal to 19.7. Also, from the results in Figure 8, it can be seen that the PVA showed a significant peak at a $2 \theta^{\circ}$ value of $20^{\circ}$ related to the semi-crystalline nature of PVA [34]. 


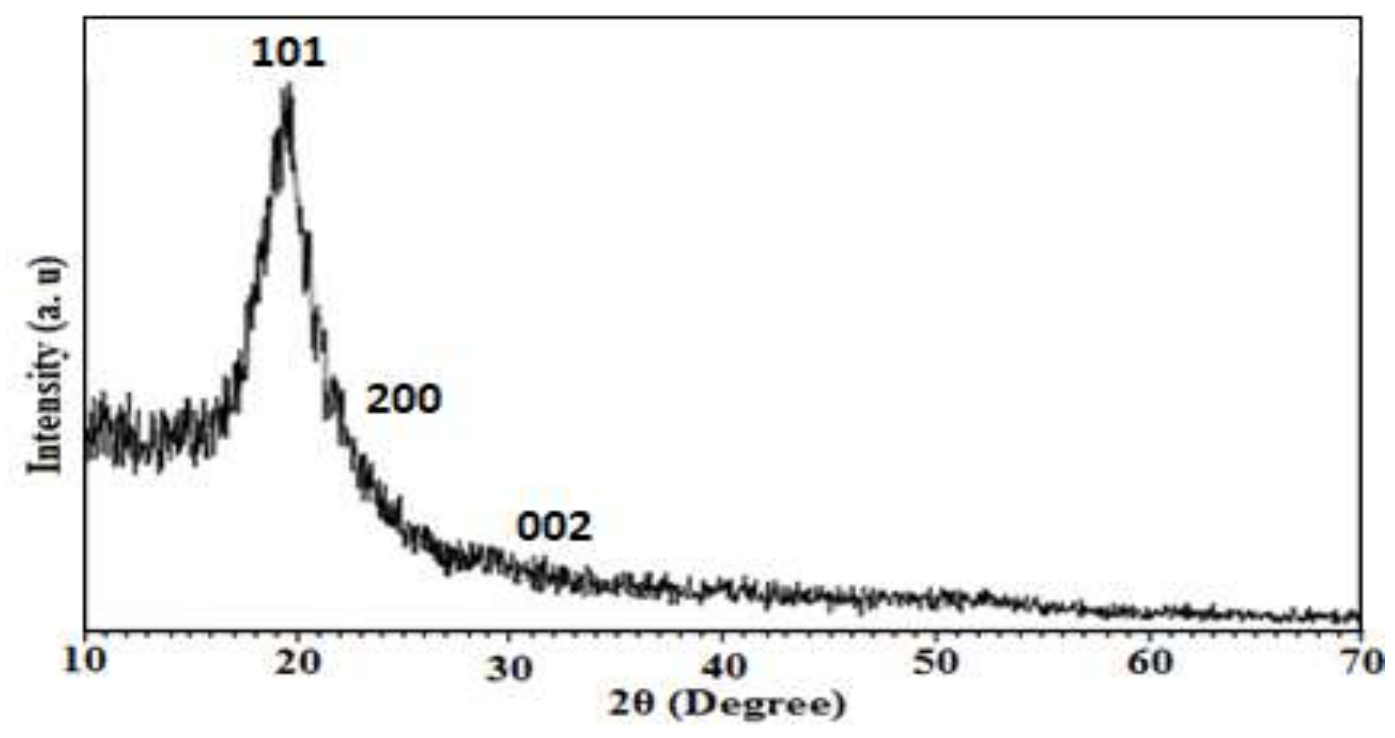

Figure 8: XRD pattern of PVA at concentration of 12 wt.\%.

\subsection{Evaluation of Morphological Results}

The morphological specifications of the synthesized nanofilters were evaluated using FE-SEM. The surface topography of the nanofibers was highly determined by the concentration of the polymeric solution and electrospinning operating conditions. In this work, the applied voltage, polymer flow rate, operating temperature, and humidity were kept constant for each polymeric solution (see Table 1). Figures 9 and 10 show FE-SEM results at high and low magnifications for the synthesized PAN and PVA air filters respectively. From the results in Figure 9, it was noted that the PAN nanofilter possess continuous and smooth nanofibers with a homogenous morphological shape. These features are highly helpful in producing an efficient air filtration process with high performance. Furthermore, the diameter of the fiber within an average of $556 \mathrm{~nm}$ with uniform distribution. Additionally, the prepared PAN 15\% nanofilter can effectively capture PMs due to its pore diameter which was in the range of $662 \mathrm{~nm}$ as calculated from the histogram drawn from SEM image analysis [35].

Figure 10 represents the FE-SEM results of PVA 12\% nonfilter also at low and high magnification. The results indicated the formation of fine and smooth nanofibers with homogenous distribution topography and looked like the spider-net. The statistical analysis indicated that the mean average nanofiber diameter of the PVA was about $92 \mathrm{~nm}$. Furthermore, the morphological results pointed that the PVA network has mean pore size of $96.8 \mathrm{~nm}$ as it was estimated by statistical analysis for the SEM images. These small pore sizes prevent completely the particulate matter (PM10 and PM2.5) from passing through the filter media and capturing them efficiently. According to many authors, the pore size of fibrous network structural and morphological specifications are key factors that determine the performance of the pollutants capturing process [15,23,25]. Usually, the nanofiber is characterized by special specifications such as the nanoporous features, large surface area, uniform size, and low operating weight. All these specifications indicated that the synthesized PVA nanofilter was the best choice for the high air quality in indoor air applications. 


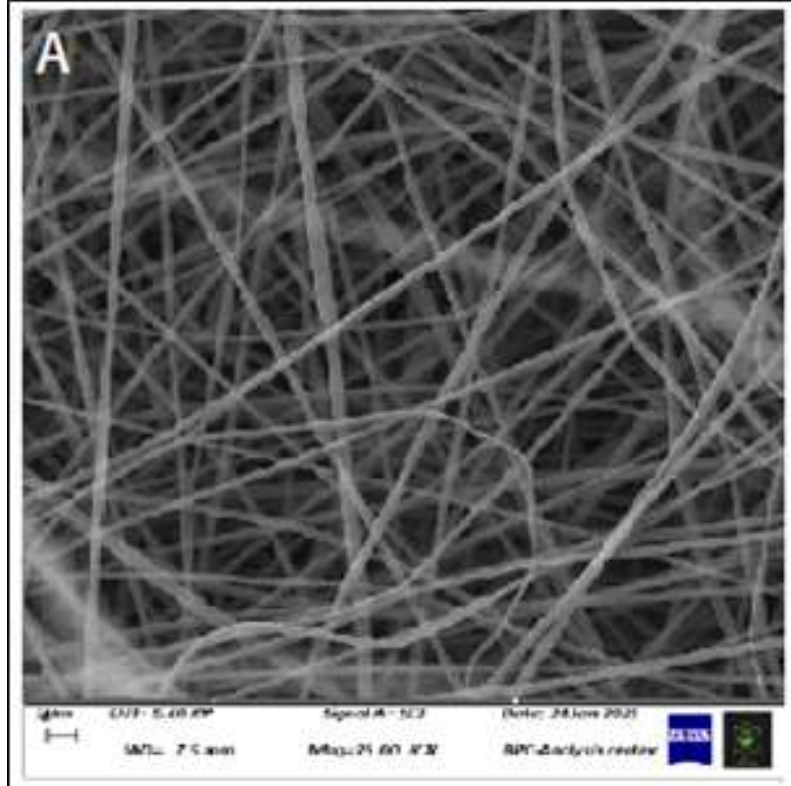

C Average fiber diameter $=556 \mathrm{~nm}$

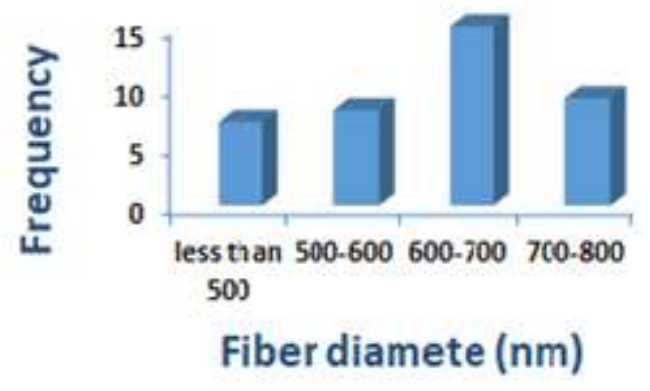

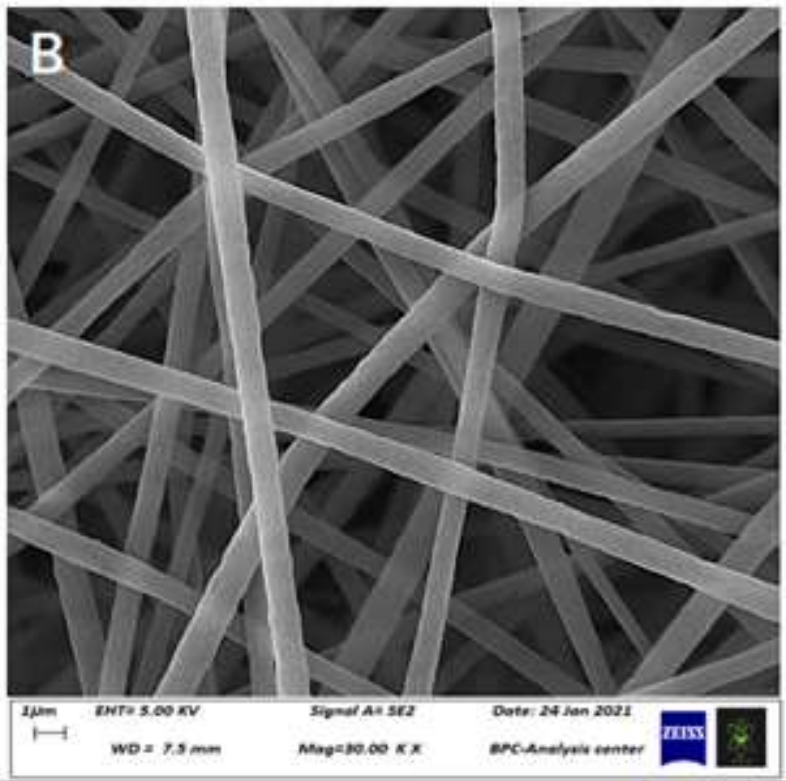

D Average pore size $=662.6 \mathrm{~nm}$

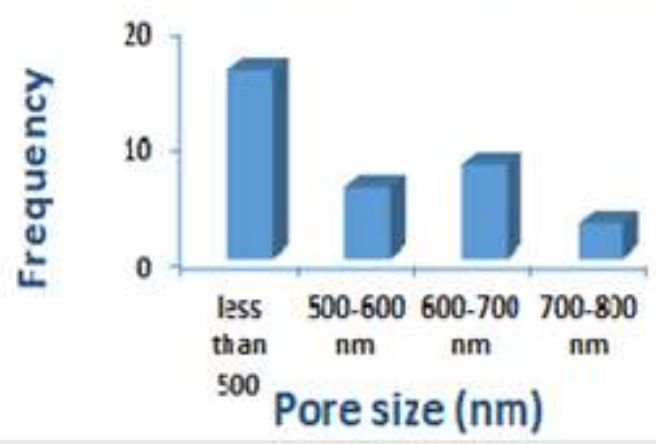

Figure 9: FE-SEM results of the synthesized PAN (15wt.\%) nanofibers A) at low magnifications, and B) at high magnifications C) Average fiber diameter D) Average pore size. 


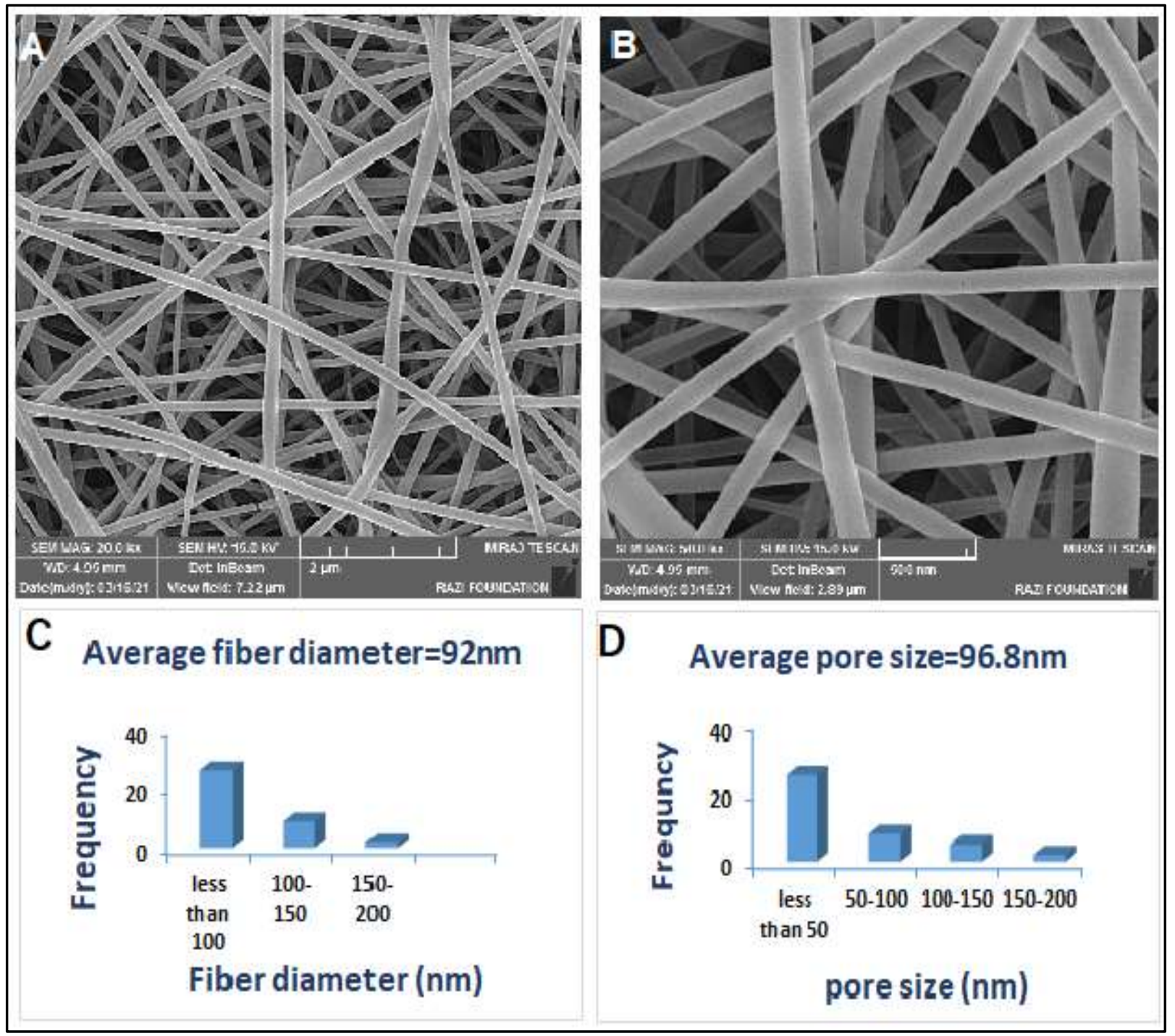

Figure 10: FE-SEM results of the synthesized PVA (12wt.\%) nanofiber A) at low magnifications, and B) at high magnifications C) Average fiber diameter D) Average pore size.

\subsection{FTIR Analysis}

The functional groups of the synthesized nanofibers were identified using FTIR spectroscopy. Figure 11 illustrates the FTIR results of the polyacrylonitrile at a concentration of $15 \mathrm{wt} . \%$. The results indicated that the absorption peak of $2243 \mathrm{~cm}^{-1}$ corresponds to the vibration band of the nitrile function group. Also, two significant peaks were appeared at 2939 and $1454 \mathrm{~cm}^{-1}$ respectively, which are attributed to the stretching and bending vibration bands of methylene and $\mathrm{CH}$ groups respectively on the nanofilter surface. The FTIR results indicated the presence of a $\mathrm{C}=\mathrm{C}$ group at $1615-1580 \mathrm{~cm}^{-1}$ and a clear band at $1750-1720 \mathrm{~cm}^{-1}$ attributed to a carbonyl group. Furthermore, there is a band position at 2935-2915 pointed to present of $(\mathrm{CH})$ group. The same observation was noted by [35,36]. On the other hand, Figure 12 shows the FTIR spectrum PVA 12 wt.\% nanofilter. obviously that some absorption peaks appeared at $1092 \mathrm{~cm}^{-1}$ assigned to the $\mathrm{O}-\mathrm{H}$ stretching vibration of the hydroxy group, $\mathrm{CH} 2$ asymmetric stretching vibration, $\mathrm{C}=\mathrm{O}$ carbonyl stretch. Also, effective peaks were presented at $1261.05 \mathrm{~cm}^{-1}$ according to ethers and aryl $-\mathrm{O}$ stretch, while, at $1736 \mathrm{~cm}^{-1}$ is attributed to carbonyl groups $[8,19]$. 


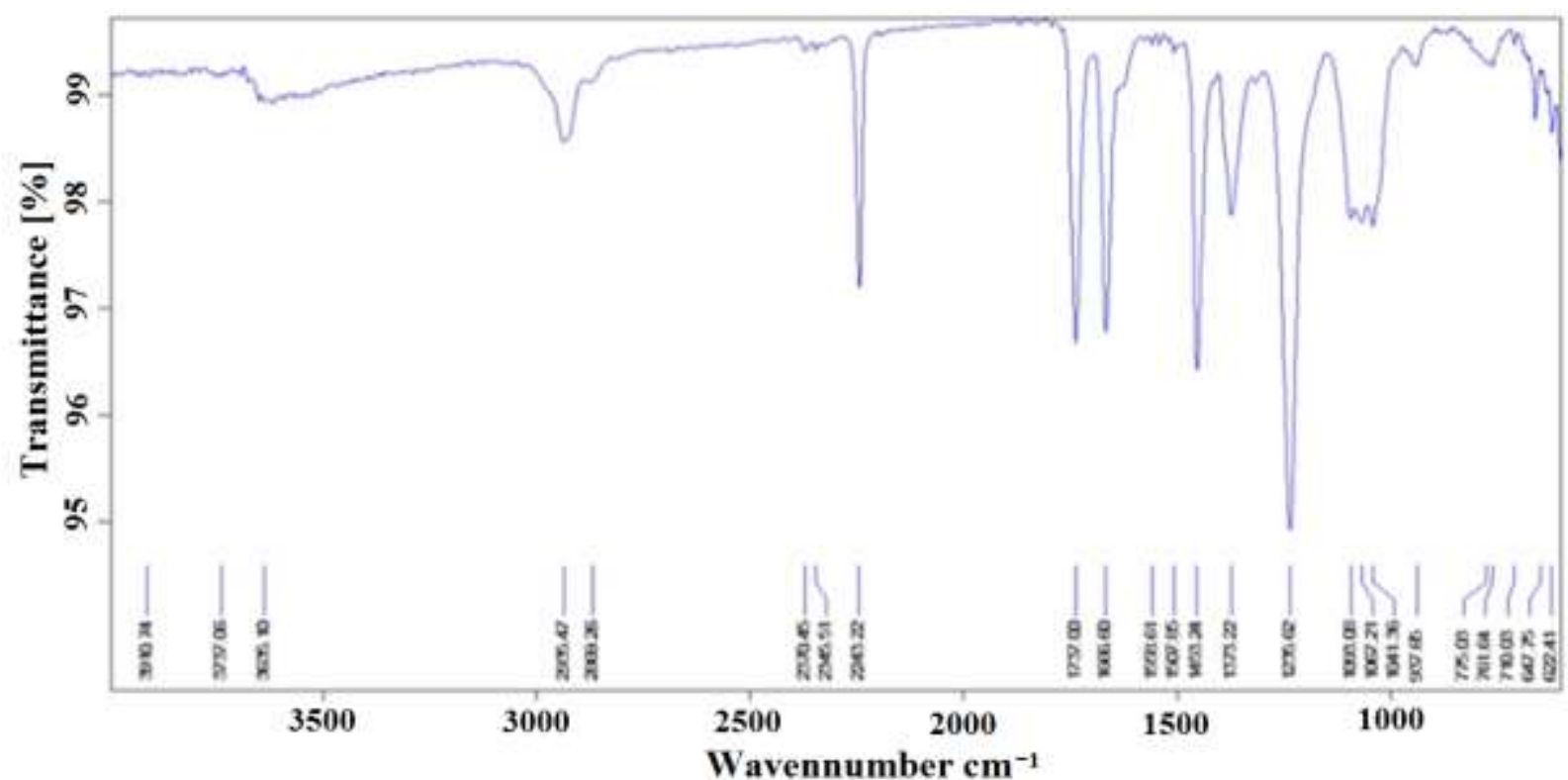

Figure 11: FTIR analysis of the prepared $12 \mathrm{wt} . \%$ air nanofilter.

Actually, the prepared nanofibers (PAN and PVA) have a high surface area due to thin nanofibers in the network structure. This area reflects the ability of the fibrous network of each filter to capture the PMs efficiently from pollute air. Finally, the functional groups that appeared in the nanofiber structure are attributed significantly to the air purification mechanism and then produce high-quality air without any PMs. This approach agrees with the work of many publications $[35,36,38]$.

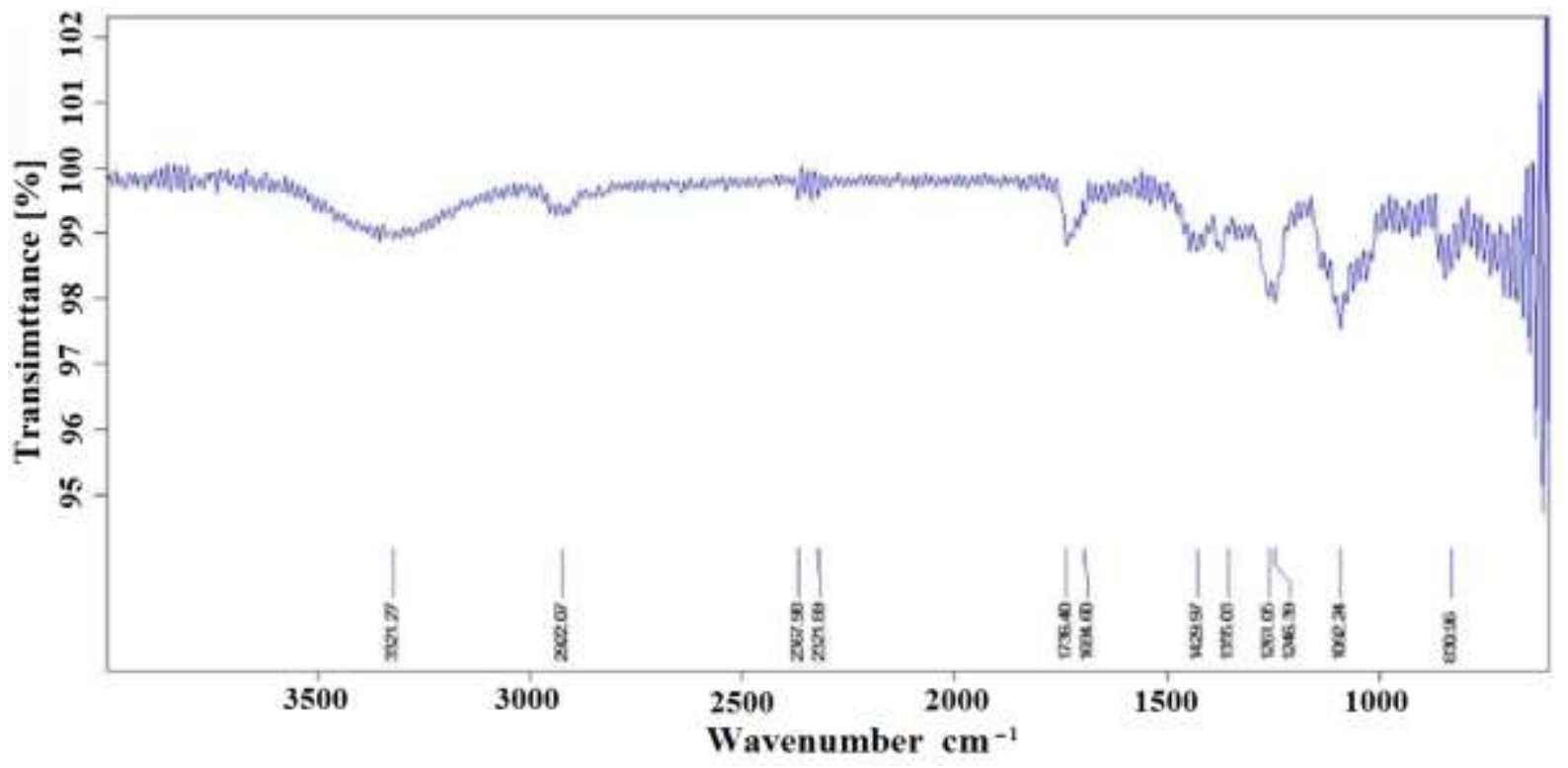

Figure 12: FTIR analysis of the prepared polyvinlyalcohol air nanofilter.

\subsection{Evaluation of Air Flow across Nanofilter}

The evaluation of airflow across the prepared nanofilters air filters will be very helpful to understand the flow characteristics and behavior of indoor air systems across these materials. The air quality in the air filtration process is very important for human health indoor in the ventilation and HVAC systems. Figure 13 illustrates the relationship between the air superficial velocity (face velocity) and the pressure drop across the PAN and PVA nanofilter material, respectively. It was noted that as the airflow velocity increased the pressure drop across the filter material increased too. The highest pressure drop was recorded to be $267 \mathrm{~Pa}$ of PVA at an air face velocity 
of $5 \mathrm{~m} / \mathrm{s}$. On the other hand, the PAN shows lower values of pressure drop due to the large pore size of the fibrous network. Then, at a face velocity of $5 \mathrm{~m} / \mathrm{s}$, the pressure drop was $185 \mathrm{~Pa}$ for the PAN nanofilter. According to the results of Haider et al. [1], Martins et al. [3], and Cheng et al. [20], the management and control of air velocity is the main factor in determining the performance through the air filter media. Then, each ventilation system keeping a constant level of air velocity for the HVAC ventilation system the range of air face velocity up to $4 \mathrm{~m} / \mathrm{s}$ while for the industrial unit the velocity arrived at $8 \mathrm{~m} / \mathrm{s}[19,25,40]$.

Moreover, according to the FE-SEM results in Figure 9, the capturing efficiency of the PMs is decreased with an increase in nanofiber size. The highly condense network textures of the prepared air nanofilter increase the ability of the filter to capture the PMs efficiently. Then, airflow across this network textures may be caused pressure drop and then reduce the permeability of filter media. Therefore, passing air through nanofiller media was estimated across the PAN and PVA nanofilter was $97 \%$ and $96 \%$, respectively. The smaller fiber diameter can capture the PM10 and PM2.5 with the high performance and acceptable face velocity and pressure drop. Moreover the efficiency of capturing PM(10 and 2.5) also depend on thickness of filters, thicker filters led to increase air

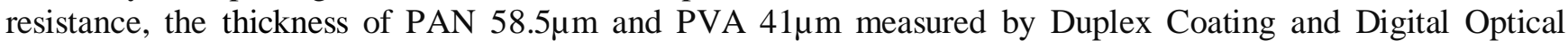
Microscope . Additionally, Figure 13 indicated that it is very harder for the PMs to pass across the nanofilter media due to the perfect synthesized network texture of the PVA nanofilter $[3,18,28]$. Furthermore, Hung et al. [7] pointed to that the smaller nanofibers improve the filtration process $(50-500 \mathrm{~nm})$ by enhancing diffusion and interception characteristics.

Finally, from an airflow characteristics point of the view, many authors indicated that as the air velocity increased the removal efficiency of PMs decreased. This is attributed the fact that high air velocity provided an increase in the passage of particles across filter material and then the movement of particles across the pores will be faster with a reduced chance for capturing the PMs. The same explanation was noted by Haider et al. [1], Omollo et al. [12], and Kim and Lee [26].

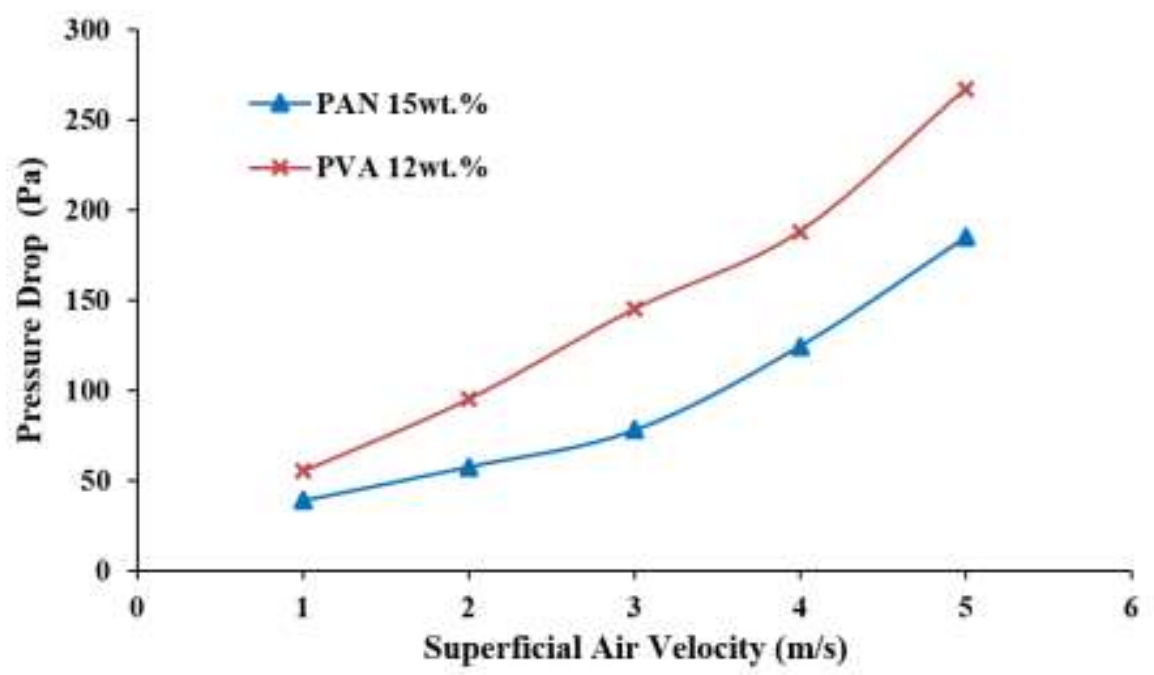

Figure 13: The relationship between space velocity and pressure drop across the PAN and PVA air nanofilters.

\section{Conclusions}

The electrospinning method was used successfully to produce air nanofilters type PAN 15wt.\% and PVA 12\% for the purpose of capturing particulate matters (PM10 and PM2.5). The characterization results indicated that the synthesized nanofilters have excellent morphological, structural, and surface specifications that allow capturing all PM10 and PM2.5 efficiently. The PVA provided the smallest pore diameter of $96.8 \mathrm{~nm}$ while PAN gave the value of $662 \mathrm{~nm}$. Then, the prepared air filter is considered highly active for providing a high air quality by the indoor air filtration through PMs capturing. Also, it was observed that the airflow velocity plays a key factor in determining the airflow performance across the synthesized air nanofilter media. It was noted that as the airflow velocity increased the pressure drop across the filter material increased and the highest pressure drop was recorded 
to be $267 \mathrm{~Pa}$ at a velocity of $5 \mathrm{~m} / \mathrm{s}$ for the PVA nanofilter. Additionally, the prepared nanofilters can be used efficiently in the air filtration process with economic feasibility.

\section{Acknowledgements}

The authors are thankful to the research unit of Design and Industrial Production at the Department of Chemical Engineering, University of Technology and electrospinning Lab at the Materials Engineering Department/ University of Technology for their scientific support to achieve this project.

\section{Conflict of Interest}

The authors declare that they have no conflict of interest.

\section{References}

[1] A. J. Haider, K. A. Sukkar, A. H. Abdalsalam, A. F. Ali, S. H. Jaber, et al., "Enhancement of the air quality and heat transfer rate of an air-conditioning system using a hybrid polypropylene nanofilter", Process Safety and Environmental Protection, vol. 149, p. 56-66, 2021.

[2] J. Matulevicius, L. Kliucininkas, T. Prasauskas, D. Buivydiene, et al., "The comparative study of aerosol filtration by electrospun polyamide, polyvinyl acetate, polyacrylonitrile and cellulose acetate nanofiber media", Journal of Aerosol Science, vol. 92, p. 27-37, 2016.

[3] N.R. Martins, and G.C. da Graça, "A simulation study of decreased life expectancy from exposure to ambient particulate air pollution (PM2.5) in naturally ventilated workspaces", Journal of Building Engineering, vol. 30, p. 101268, 2020.

[4] M.A. Moktadir, S.M. Ali, S. Kusi-Sarpong, et al., "Assessing challenges for implementing Industry 4.0: Implications for process safety and environmental protection", Process Safety and Environmental Protection, vol. 117, p. 730-741, 2018.

[5] M. Cao, F. Gu, C. Rao, J. Fu, et al., "Improving the electrospinning process of fabricating nanofibrous membranes to filter PM2.5", Science of the Total Environment, vol. 666, p. 1011-1021, 2019.

[6] S.K .Ghosh, P. Adhikary, S. Jana, A. Biswas, V. Sencadas, S.D. Gupta, B. Tudu, et al., "Electrospun gelatin nanofiber based self-powered bio-e-skin for health care monitoring", Nano Energy, vol. 36, p. 166-175, 2017.

[7] C.H. Hung, and W.W.F. Leung, "Filtration of nano-aerosol using nanofiber filter under low Peclet number and transitional flow regime", Separation and purification technology, vol.79, p.34-42, 2011.

[8] X. Ding, Y. Li, Y. Si, X. Yin, J. Yu, et al., "Electrospun polyvinylidene fluoride/SiO2 nanofibrous membranes with enhanced electret property for efficient air filtration", Composites Communications, vol. 13, p. 57-62, 2019.

[9] V.S. Hingwe, K.A. Koparkar, N.S. Bajaj, et al., "Optical properties of one-dimensional hybrid PVA/YVO4: Eu3+ nanofibers synthesized by electrospining", Optik, vol. 140, p. 211-215, 2017.

[10] S. Su, T. Bedir, C. Kalkandelen, A.O. Başar, H.T. Şaşmazel, C.B. Ustundag, M. Sengor, et al., "Coaxial and emulsion electrospinning of extracted hyaluronic acid and keratin based nanofibers for wound healing applications", European Polymer Journal, vol. 142, p. 110158, 2020.

[11] M. J Haider, D. S. Ahmed, M. R. Mohammad, et al., "Modification of functionalized multi walled carbon nanotubes by olive oil as economic method for bacterial capture and prevention", Biosciences Biotechnology Research Asia, vol. 14, no. 4, p.1513-1522, 2017.

[12] E. Omollo, C. Zhang, J.I. Mwasiagi, et al., "Electrospinning cellulose acetate nanofibers and a study of their possible use in high-efficiency filtration", Journal of Industrial Textiles, vol. 45, p. 716-729, 2016.

[13] K.A. Sukkar, S.A. Duha, A.A. Hussein, et al., "Synthesis and characterization hybrid materials ( $\mathrm{TiO}_{2} / \mathrm{MWCNTs}$ ) by chemical method and evaluating antibacterial activity against common microbial pathogens", Acta Physica Polonica, vol. 135, p. 588-592, 2019. 
[14] E. Uslu, M. Gavgali, M.O. Erdal, Ş. Yazman, et al., "Determination of mechanical properties of polymer matrix composites reinforced with electrospinning N66, PAN, PVA and PVC nanofibers: A comparative study", Materials Today Communications, vol. 26, p. 101939, 2020.

[15] T. Xia, Y. Bian, L. Zhang, and C. Chen, "Relationship between pressure drop and face velocity for electrospun nanofiber filters", Energy and Buildings, vol. 158, p. 987-999, 2018.

[16] A. Zhang, H. Li, A. Zhang, J. Zhou, et al., "High-temperature bearable polysulfonamide/polyacrylonitrile composite nanofibers for high-efficiency PM2.5 filtration", Composites Communications, vol. 23, p. 100582, 2020.

[17] L.J. Basri, H.N. Mohesn, and K.A. Sukkar, "Treatment of industrial water by nano technology", Journal of Petroleum Research \& Studies, vol. 8, p. 166-188, 2018.

[18] C.W. Chang, and W.C. Lai, "A strategy for preparing solid polymer electrolytes via the electrospinning process", Journal of the Taiwan Institute of Chemical Engineers, vol. 116, p. 279-285, 2020.

[19] S. A. Ajeel, K. A. Sukkar, and N. K. Zedin, "Chemical extraction process for producing high purity nanosilica from Iraqi rice husk", Engineering and Technology Journal, vol. 39, no. 1, p. 56-63, 2021.

[20] T. Cheng, S. Li, L. Xu, and A. Ahmed, "Controllable preparation and formation mechanism of nanofiber membranes with large pore sizes using a modified electrospinning", Materials \& Design, vol. 178, p. 107867, 2019.

[21] F.A. Chayad, A.R. Jabur, and N.M. Jalal, "Effect of $\mathrm{NaCl}$ solution addition on improving some of the physical properties of Nylon 6 solutions used for electro spinning purpose", Engineering and Technology Journal, vol. 34, p. 1265-1274, 2016.

[22] S. A. Karthick, and N. Gobi, "Nano silver incorporated electrospun polyacrylonitrile nanofibers and spun bonded polypropylene composite for aerosol filtration", Journal of Industrial Textiles, vol.46, no.6, p. 13421361, 2017.

[23] H. Tian, G. Guo, X. Fu, Y. Yao, L. Yuan, et al., "Fabrication, properties and applications of soy-protein-based materials", International journal of biological macromolecules, vol. 120, p. 475-490, 2018.

[24] A. Zulfi, D.A. Hapidin, M.M. Munir, F. Iskandar, et al.,, "The synthesis of nanofiber membranes from acrylonitrile butadiene styrene (ABS) waste using electrospinning for use as air filtration media", RSC advances, vol. 9, p. 30741-30751, 2019.

[25] Q. Cao, X. Meng, S. Tan, Z. Xin, L.S. Turng, J. Li, Z. Yao, Z. Zhai, et al., "Electrospun bead-in-string fibrous membrane prepared from polysilsesquioxane-immobilising poly (lactic acid) with low filtration resistance for air filtration", Journal of Polymer Research, vol. 27, p. 1-13, 2020.

[26] J. H. Kim, and J. S. Lee, "Development of Polydiacetylene Embedded Polyurethane Nanocomposites as a mask for sensing and filtering fine dust", Fibers and Polymers, vol. 22, p. 489-497, 2021.

[27] N.A. Barakat, A.M. Hamza, S.S. Al-Deyab, A. Qurashi, et al., "Titanium-based polymeric electrospun nanofiber mats as a novel organic semiconductor", Materials Science and Engineering, vol. 177, p.34-42, 2012.

[28] A.H. Oleiwi, A.R. Jabur, and Q.F. Alsalhy, "Preparation of polystyrene/polyacrylonitrile blends by electrospinning technique", In Journal of Physics: Conference Series, vol. 1879, p. 022065, 2021.

[29] H.A. Sharhan, Z.N. Rasheed, and J.K. Oleiwi, "Synthesis and Physical Characterization of PMMA/PP and PMMA/PAN Composites for Denture Applications", Journal of Applied Sciences and Nanotechnology, vol. 1, p. 13-23. 2021.

[30] M. Carugno, D. Consonni, G. Randi, D. Catelan, L.Grisotto, P.A. Bertazzi, A. Biggeri, et al., "Air pollution exposure, cause-specific deaths and hospitalizations in a highly polluted Italian region", Environmental Research, vol. 147, p. 415-424, 2016.

[31] M.A. Al-Kinani, A.J. Haider, and S. Al-Musawi, "Study the effect of laser wavelength on polymeric metallic nanocarrier synthesis for curcumin delivery in prostate cancer therapy: In vitro study. Journal of Applied Sciences and Nanotechnology, vol. 1, p. 43-50, 2021. 
[32] Z. Wang, W.W. Delp, and B.C. Singer, "Performance of low-cost indoor air quality monitors for PM2. 5 and PM10 from residential sources", Building and Environment, vol. 171, p. 106654, 2020.

[33] A.M. Hamza, E.D. Alhtheal, and A.K. Shakir, "Enhancement the Efficiency of ZnO nanofiber mats antibacterial Using Novel PVA/Ag nanoparticles", Energy Procedia, vol. 119, p.615-621, 2017.

[34] A. J. Haider, Z. Al-Shibaany, R. Hawy, et al., "Impact of PS/PMMA Polymer Ratios with Nanocomposite Material on Optical and Morphological Properties", Ziggurat Journal of Materials Technology (ZJMT), vol. 1, no. 1, p.23-32, 2020.

[35] Z. Khedaer, D. Ahmed, and S. Al-Jawad, Investigation of morphological, optical, and antibacterial properties of hybrid ZnO-MWCNT prepared by sol-gel. Journal of Applied Sciences and Nanotechnology, vol. 1, p. 6677, 2021.

[36] A.R. Jabur, F.A. Chayad, and N.M. Jalal, "Fabrication and characterization of nylon 6/MWCNTs conductive polymer by electrospinning technique", International Journal of Thin Films Science and Technology, vol. 5, p.1-9, 2016.

[37] S.B. Aziz, O.G. Abdullah, S.A. Hussein, et al., "Effect of PVA blending on structural and ion transport properties of CS: AgNt-based polymer electrolyte membrane", Polymers, vol. 9, p.622, 2017.

[38] R. Jabbar and N.N. Hussein, Evaluation the antibacterial activity of biosynthesis silver nanoparticles by lactobacillus gasseri bacteria. Journal of Applied Sciences and Nanotechnology, vol. 1, p. 86-95, 2021.

[39] B. Fryczkowska, D. Biniaś, C. Ślusarczyk, J. Fabia, et al., "Impact of forming on the structure and separation properties of polyacrylonitrile membranes with polyaniline addition", Desalination and Water Treatment, vol.108, p.27-39, 2018.

[40] T.P. Nguyen, A.D. Le, T.B. Vu, et al., "Investigations on photoluminescence enhancement of poly (vinyl alcohol)-encapsulated Mn-doped ZnS quantum dots", Journal of Luminescence, vol.192, p.166-172, 2017. 